\title{
Parental engagement in children's STEM education. Part II: Parental attitudes and motivation
}

\author{
Carlos C. F. Marotto and Marina Milner-Bolotin \\ The University of British Columbia, Canada
}

This mixed-methods case study examines parental motivation for participation in a Canadian university-based STEM outreach event. Parents responded to a postevent questionnaire that was followed by individual interviews. The quantitative part revealed how and why parents engaged with their children's STEM education. Surprisingly, neither university admission requirements nor STEM-related job opportunities were top motivating factors. The qualitative part indicated that some parents found it challenging to connect their children's learning experience in school with the government-mandated curriculum or with their own experiences. Most interviewees were satisfied with their children's STEM education and considered family support crucial in this process.

Keywords: informal and formal STEM education, parental engagement, STEM education, STEM outreach

\author{
Article details \\ LUMAT General Issue \\ Vol 6 No 1 (2018), 60-86 \\ Received 14 August 2017 \\ Accepted 16 March 2018 \\ Published 5 May 2018 \\ Updated 21 June 2018 \\ Pages: 27 \\ References: 14 \\ DOI:10.31129/LUMAT.6.1.293 \\ Contact: \\ ccfmarotto@hotmail.com \\ www.lumat.fi
}

This project has been approved by the University of British Columbia Ethics Review Board - H16-02469. All the people in the photographs have given their consent to be photographed. All the names of the interviewees have been changed to pseudonyms to protect their privacy.

\section{Introduction}

There is a universal concern about student disengagement from science, technology, engineering and mathematics (STEM) disciplines (Hathaway \& Kallerman, 2012; Let's Talk Science, 2013, 2017; O'Grady, Deussing, Scerbina, Fung, \&Muhe, 2016; The National STEM Learning Network, 2017). At the same time, parents play a vital role in their children's STEM education (Fine, 1993; Ing, 2014; Kaya \& Lundeen, 2010; Let's Talk Science, 2015; Perera, 2014). Therefore, it is important to examine how parents can be supported in helping their children to meaningfully engage with STEM. To the best of our knowledge, there is limited research examining this problem.

This is the second paper in a two-paper series examining how parents can be encouraged and supported in engaging with their children's formal (in-school) and informal (out-of-school) STEM education. The meta-analysis of the literature presented in Paper 1 identified five major themes:

1. The challenges of supporting parents with children's STEM education 
2. STEM education as a bridge between school and family

3. STEM education as a gateway for children's future economic success

4. STEM education as a vehicle for promoting student communication skills

5. The role of hands-on inquiry-based activities in enhancing student engagement.

The goal of this paper (Paper 2) is to examine parental attitudes towards formal and informal STEM education; their motivation for supporting their children; and their views on how schools can support families' engagement with STEM. To achieve this goal, we asked the following research questions (RQ).

RQ1: What are parents' attitudes towards informal STEM education? The challenges of supporting parents with children's STEM education

RQ2: From the parents' perspective, what are effective ways to engage children in STEM education?

RQ3: What motivates parents to engage their children with STEM education?

RQ4: From the parents' perspective, what are effective ways for schools to encourage parents to support their children's STEM education?

In the next section, we describe the study methodology. It comprises the study's context, participants, instruments for data collection, and the data analysis method.

\section{Methodology}

\subsection{Study Context}

Family Mathematics and Science Day (FMSD) is a free annual family-oriented outreach event that takes place on a fall weekend at the University of British Columbia (UBC) Faculty of Education. It consists of 60+independent self-contained interactive stations, facilitated by students and faculty, and is attended by hundreds of guests (Figures 1and 2) (Milner-Bolotin \& Milner, 2017). To engage visitors of different ages and backgrounds, FMSD has a flexible structure so the visitors choose stations according to their interests. Currently we are developing a YouTube channel with the FMSD activities (Milner-Bolotin, 2017). Since UBC campus has a large residential community in its vicinity, many attendees are connected to it. Many "out-of-town" families also attend the event. 


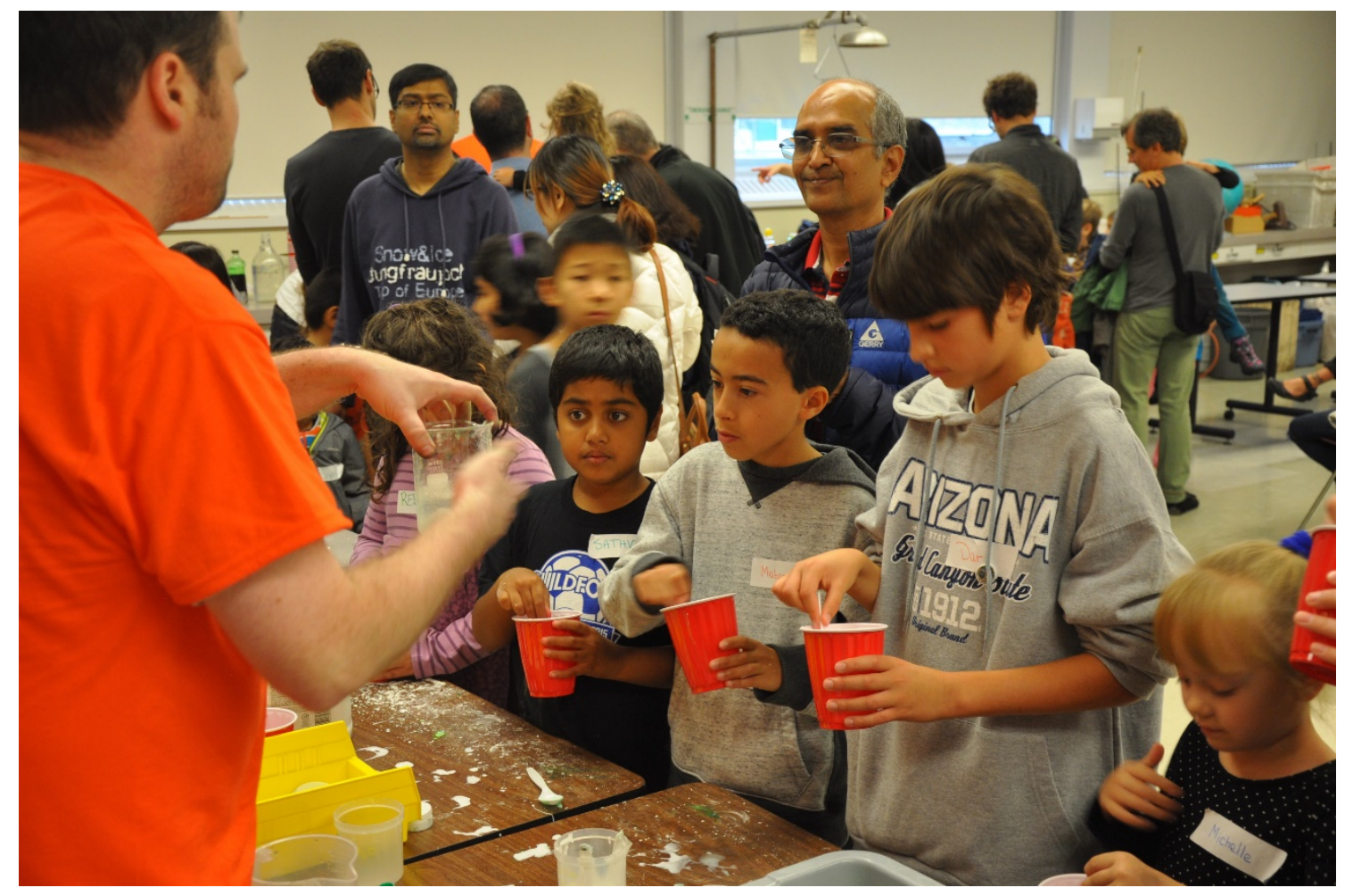

Figure 1. An event volunteer engages visitors in making and exploring Newtonian fluids.

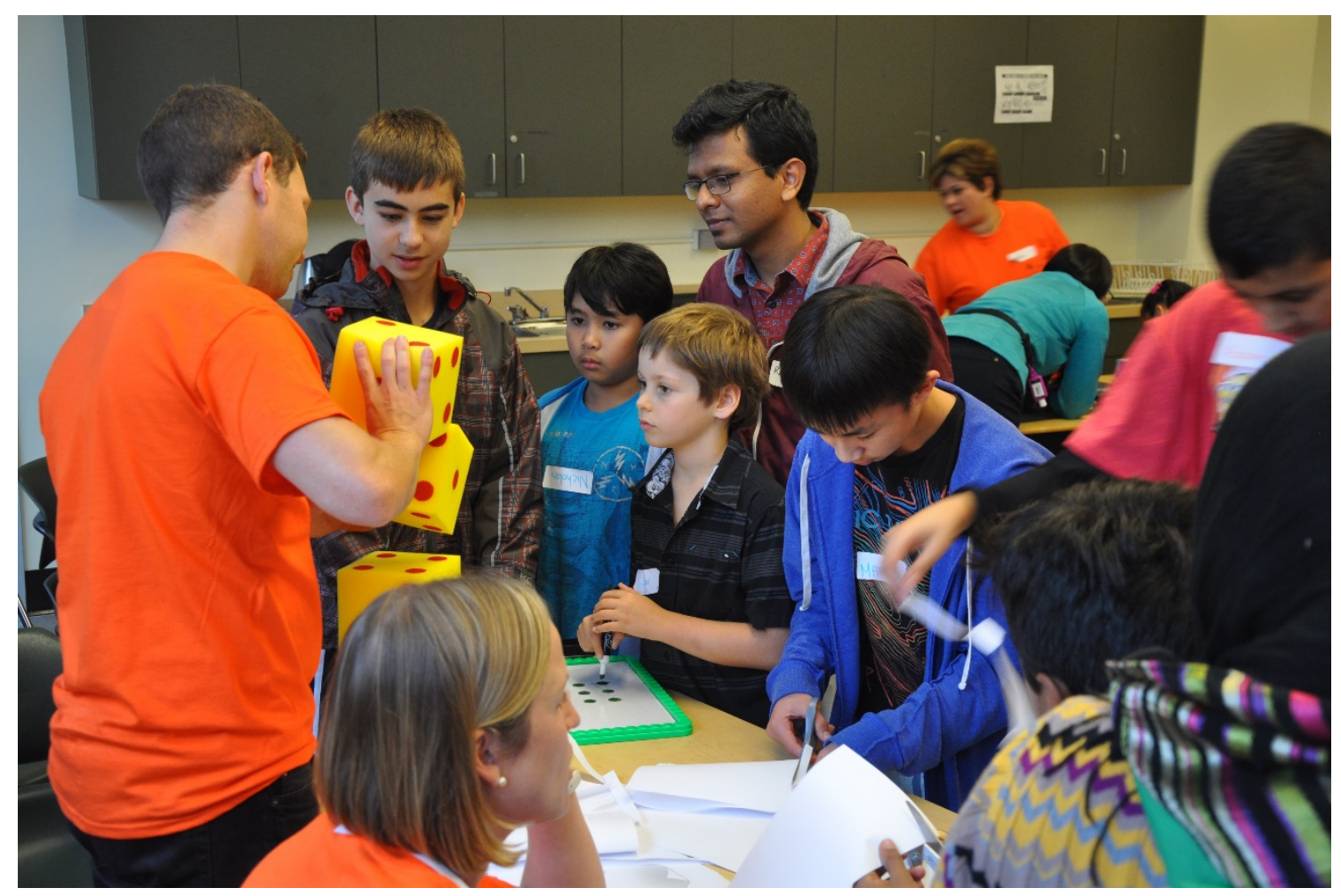

Figure 2. An event volunteer engages visitors in solving mathematical puzzles. 


\subsection{Participants and Instruments}

The study was approved by UBC's Ethics Board. Only the adults who attended the 2016 FMSD were eligible to participate. Adult attendees were contacted by email shortly after the event and invited to participate in this study by responding to an online questionnaire (Appendix). Table 1 gives an overview of the 16 questions that comprise the questionnaire. The research team produced and piloted the questionnaire. To expand on the questionnaire responses, we conducted follow-up semi-structured individual interviews. Their participation was voluntary and unpaid.

Table 1. Overview of the Study Questionnaire.

\begin{tabular}{lc}
\hline Item/question focus & \# of items/questions \\
\hline Demographics: adult's relationship with the child, adult's place of birth, age, & 6 \\
and level of education & 3 \\
Adult's attitudes towards FMSD & 1 \\
Adult's reasons for encouraging children in STEM & 2 \\
Ways to encourage children's STEM engagement & 1 \\
Level of familiarity with STEM curriculum & 1 \\
Importance of parental involvement with STEM & 1 \\
Event feedback & 1 \\
Invitation to participate in a follow-up individual interview & \\
\hline
\end{tabular}

\subsection{Methods}

This research followed a case-study design (Figure 3). A convenience sampling was used due to the substantial number of parents who registered for and attended the 2016 FMSD. All adults who attended the event were invited to respond to the questionnaire. Then, questionnaire respondents were invited to take part in individual interviews. Twenty-nine adults responded to the questionnaire; six of whom were later interviewed. Three of the six follow-up interviews were conducted face-to-face; the other three through Skype. Once interviews were transcribed, emerging themes were identified. Afterward, the transcripts were revisited and interviewees' comments were coded according to these pre-identified themes. This was done with the support of NVivo 11 (QSR International, 2016). Data from questionnaire were quantitatively analysed, whereas data from the interviews were qualitatively analysed. Subsequently all data were triangulated to address the issues of credibility and validity (Mathison, 1988). 


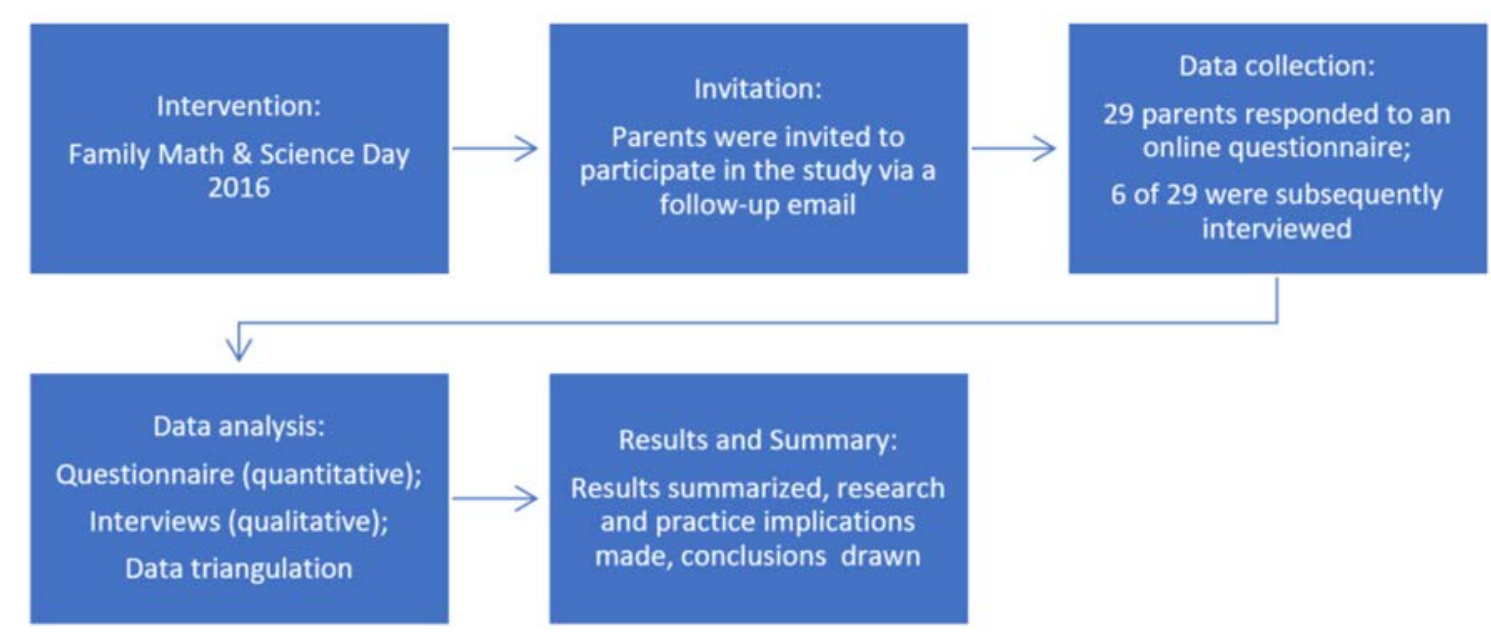

Figure 3. Study design.

\section{Results}

As mentioned earlier, the quantitative results of the study are based on the questionnaire responses while the qualitative results were gleaned from the interviews. These results were triangulated to enable a better understanding of the study's findings.

\subsection{Quantitative Results}

\subsubsection{Participants' Demographics}

Like UBC, Vancouver has a multi-cultural international population. A high ratio of families from Asian countries was a noticeable aspect of visitors' demographics in the 2016 FMSD. Table 2 shows participants' demographics.

Table 2. Overview of Participants' Demographics.

\begin{tabular}{llll}
\hline $\begin{array}{l}\text { Place of Birth } \\
\text { Country/Region }\end{array}$ & $\begin{array}{l}\text { \# Participants } \\
\text { (percent) }\end{array}$ & $\begin{array}{l}\text { Age bracket } \\
\text { (years) }\end{array}$ & \# Participants (percent) \\
\hline Asia & $11(37.9 \%)$ & 24 or younger & 0 \\
Canada & $08(27.6 \%)$ & $25-34$ & $02(6.90 \%)$ \\
Europe & $04(13.8 \%)$ & $35-44$ & $18(62.1 \%)$ \\
Latin America & $02(6.80 \%)$ & $45-54$ & $09(31.0 \%)$ \\
Middle East & $01(3.4 \%)$ & $55-64$ & 0 \\
USA & $03(10.3 \%)$ & 65 or older & 0 \\
\hline
\end{tabular}


Table 3 shows participants' level of science and mathematics education. Interestingly, most participants studied science and mathematics at undergraduate level or beyond. This shows that they have a relatively elevated level of STEM education.

Table 3. Overview of Participants' Science and Mathematics Education

\begin{tabular}{llll}
\hline $\begin{array}{l}\text { Participants' highest level of } \\
\text { science education }\end{array}$ & $\begin{array}{l}\text { \# Participants } \\
\text { (percent) }\end{array}$ & $\begin{array}{l}\text { Participants' highest level of } \\
\text { mathematics education }\end{array}$ & $\begin{array}{l}\text { \# Participants } \\
\text { (percent) }\end{array}$ \\
\hline $\begin{array}{l}\text { Secondary school } \\
\text { High school }\end{array}$ & - & Secondary school & $01(3.4 \%)$ \\
$\begin{array}{l}\text { Undergraduate level or } \\
\text { beyond }\end{array}$ & $10(35.7 \%)$ & $\begin{array}{l}\text { High school } \\
\text { Undergraduate level or beyond }\end{array}$ & $\begin{array}{l}05(17.2 \%) \\
23(78.2 \%)\end{array}$ \\
\hline
\end{tabular}

\subsubsection{Parental reasons to encourage their children to engage with STEM}

Table 4 shows participants' reasons for encouraging their children to engage with STEM. In these questions, the participants could select as many reasons as they wished.

Table 4. Participants' Reasons to Encourage Their Children to Engage with STEM.

\begin{tabular}{ll}
\hline Reasons & $\begin{array}{l}\text { \# of participants } \\
\text { (percent) }\end{array}$ \\
\hline STEM has many everyday life applications. & $27(93.1 \%)$ \\
STEM-related subjects are fun. & $26(89.7 \%)$ \\
STEM provides an interesting way to learn about the natural world. & $26(89.7 \%)$ \\
STEM helps students to develop critical thinking skills. & $25(86.2 \%)$ \\
STEM is at the core of modern technological innovations. & $24(82.8 \%)$ \\
STEM will open many exciting and well-paid future job opportunities for children. & $14(48.3 \%)$ \\
STEM is required subjects for university admissions. & $9(31 \%)$ \\
Respondents' professions are related to STEM and their children are expected to & $4(13.8 \%)$ \\
follow their paths. & \\
\hline
\end{tabular}

\subsubsection{Parental appreciation of Family Math and Science Day}

FMSD was considered "very interesting" by 23 (79.3\%) and "interesting" by 6 participants (21.7\%). No participant considered the event "not so interesting". Besides, all 29 participants would recommend FMSD to others. 
3.1.4 Effective ways for parents to encourage children to study STEM

Table 5 shows what participants consider as the most effective ways to encourage their children to study STEM-related subjects. They could select as many reasons as they wanted.

Table 5. Participants Views on the Most Effective Ways to Encourage Their Children to Study STEM-Related Subjects.

\begin{tabular}{ll}
\hline Effective ways to encourage children to study STEM & $\begin{array}{l}\text { \# of participants } \\
\text { (percent) }\end{array}$ \\
\hline Taking children to science centres. & $26(89.7 \%)$ \\
Accompanying children to STEM-related events. & $26(89.7 \%)$ \\
Helping children with their STEM-related homework. & $24(82.8 \%)$ \\
Asking about their children's School STEM programs. & $22(75.9 \%)$ \\
Encouraging children to watch STEM-related television shows. & $21(72.4 \%)$ \\
Pointing out the role of STEM in important societal and political issues. & $18(62.1 \%)$ \\
Enrolling children in after-school STEM programs. & $15(51.7 \%)$ \\
\hline
\end{tabular}

3.1.5 Effective ways for schools to encourage parents to support their children's STEM education

Table 6 shows participants' views on the topic of how schools might encourage parents to support their children's STEM education. The participants could select as many reasons as they wished.

Table 6. Participants' Views on How Schools Can Encourage Parents to Support Their Children's STEM Education

\begin{tabular}{ll}
\hline Participants' views on how schools can engage parents & $\begin{array}{l}\text { \# of participants } \\
\text { (percent) }\end{array}$ \\
\hline Promoting STEM-related events in school. & $25(86.2 \%)$ \\
Informing parents about STEM-related activities in science centres. & $24(82.8 \%)$ \\
Creating a classroom blog a parent can access from home. & $21(72.4 \%)$ \\
Establishing a direct line of communication between teacher and parents. & $19(65.5 \%)$ \\
Assigning homework activities that require parental involvement or & $9(31 \%)$ \\
support. & \\
\hline
\end{tabular}

\subsubsection{Parental level of familiarity with their children's school STEM program}

Seventeen participants (60.7\%) considered themselves either "very familiar" or "somewhat familiar" with their children's school STEM program; the other 10 (35.7\%) considered themselves "not familiar" with it. There were 27 responses to this question. Furthermore, 26 participants (89.6\%) considered parental involvement in STEM 
education either "very important" or "important". There were 26 responses to this question.

\subsection{Qualitative Results}

In this section, we describe the qualitative analysis and the main findings from the six interviews conducted in the study. After carefully reading the transcribed interviews, we identified recurring topics, labeled as nodes in NVivo (Table 7). Then after comparing the nodes in the context of different interviews, we merged some of them to identify larger themes and allow for a deeper analysis.

Six of the 29 questionnaire respondents participated in semi-structured openended individual interviews. After analyzing the interview transcripts, and identifying ten emerging themes, ten corresponding nodes were created in NVivo. Subsequently, specific comments by the interviewees were coded to a matching NVivo node (theme). The number of comments and their content were carefully examined (Table 7).

Table 7. Number of Comments by All Interviewees Coded for Each of the Ten Emerging Themes

\begin{tabular}{|c|c|c|}
\hline Node \# & Theme & \# of comments \\
\hline 1 & Parental attitudes towards STEM, including their own experiences. & 66 \\
\hline 2 & Parental appreciation of informal STEM education for their children. & 60 \\
\hline 3 & $\begin{array}{l}\text { Parental interest in providing STEM enrichment activities for their } \\
\text { children in addition to school. }\end{array}$ & 53 \\
\hline 4 & $\begin{array}{l}\text { Parental perception of the value of interactive hands-on STEM } \\
\text { enrichment for their children. }\end{array}$ & 48 \\
\hline 5 & $\begin{array}{l}\text { Parental confidence in their abilities to support or mentor their } \\
\text { children in STEM in a meaningful way. }\end{array}$ & 44 \\
\hline 6 & Parental satisfaction of their children's STEM education. & 41 \\
\hline 7 & Parental understanding of K-12 BC educational system. & 35 \\
\hline 8 & $\begin{array}{l}\text { Parental view of how well their children are being prepared for } \\
\text { future STEM education. }\end{array}$ & 31 \\
\hline 9 & Parental knowledge of their children's school STEM curriculum. & 29 \\
\hline 10 & $\begin{array}{l}\text { Parental level of comfort in communicating their concerns about } \\
\text { STEM education to their children's teachers. }\end{array}$ & 18 \\
\hline
\end{tabular}


3.2.1 Parents' attitudes towards and appreciation for STEM, and their interest in children STEM enrichment

Figure 4 shows the number of comments coded for "Parents' attitudes towards STEM education", "Parental appreciation of informal STEM education for their children", and "Parental interests in providing their children with STEM enrichment". All six interviewees expressed a positive attitude towards and great appreciation for formal and informal STEM education. Besides, they expressed a great interest in providing their children with STEM enrichment. No distinction was found between the interviewees who have STEM-related professional careers and those who have not studied STEM-related subjects beyond secondary school.

Visiting science centres was mentioned by five interviewees as an important way to motivate their children to engage with STEM. Four of the six interviewees reported being current or former members of Science World at Telus World of Science in Vancouver. The Vancouver Aquarium was also named as an important family destination. UBC Beaty Biodiversity Museum and Botanical Garden, and science centres in Prince George, Seattle and San Francisco were also mentioned. Moreover, all six interviewees reported taking their children to STEM outreach events. Apart from FMSD, The Faraday Show, Lego shows and an event at Simon Fraser University were also mentioned. Furthermore, outdoor-learning activities, math clubs, summer camps, robotics, activities with animals, and courses in the Vancouver Aquarium were also named. Lastly, all six interviewees reported doing school-related activities at home with their children. Extra-curricular activities, such as experiments, watching STEM-related videos, accessing STEM websites and computer simulations were also mentioned as part of family routine. 


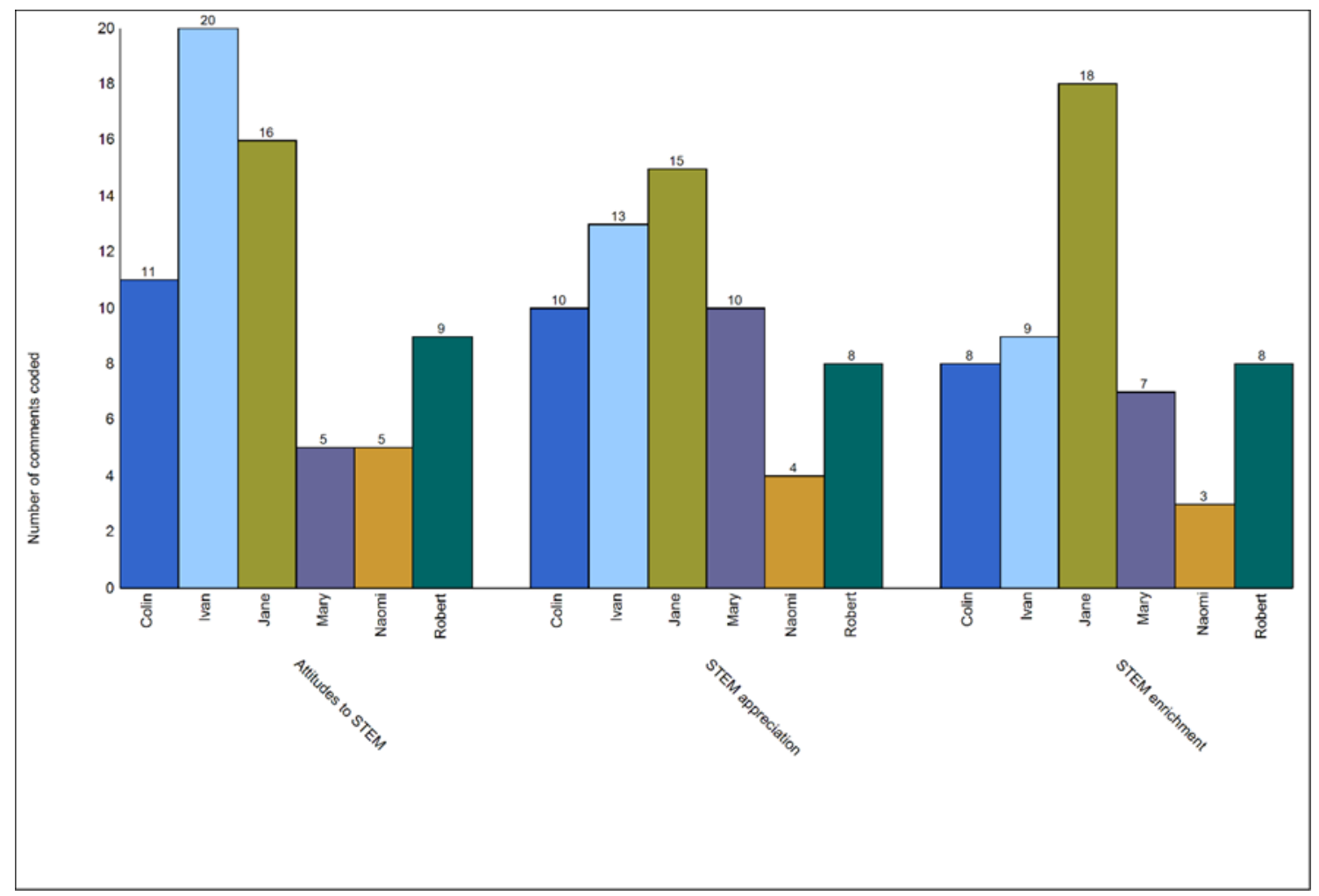

Figure 4. Number of comments on parental attitudes towards and appreciation for STEM education, and parental interest in providing STEM enrichment to their children.

\subsubsection{Parent's regard for hands-on interactive activities}

Figure 5 shows the number of comments coded for "Parental appreciation of STEM hands-on interactive activities". All six interviewees (the names used in the paper are pseudonyms) expressed their appreciation for hands-on interactive activities to raise their children's curiosity and interest. For them, FMSD was exemplary due to the variety of activities available and the way they were facilitated. For them, this combination contributed to create a positive attitude in parents and children.

Interviewees also gave examples of activities performed at home with their children. Colin mentioned one experiment in which he and his children used steel wool and peroxide to learn about rusting. Ivan and his daughter tested the effect of salt on the melting rate of snow. Jane helped her daughter run a lemonade stand whereby mathematical calculations were employed to calculate the amount of ingredients needed and the profit made in the process. 


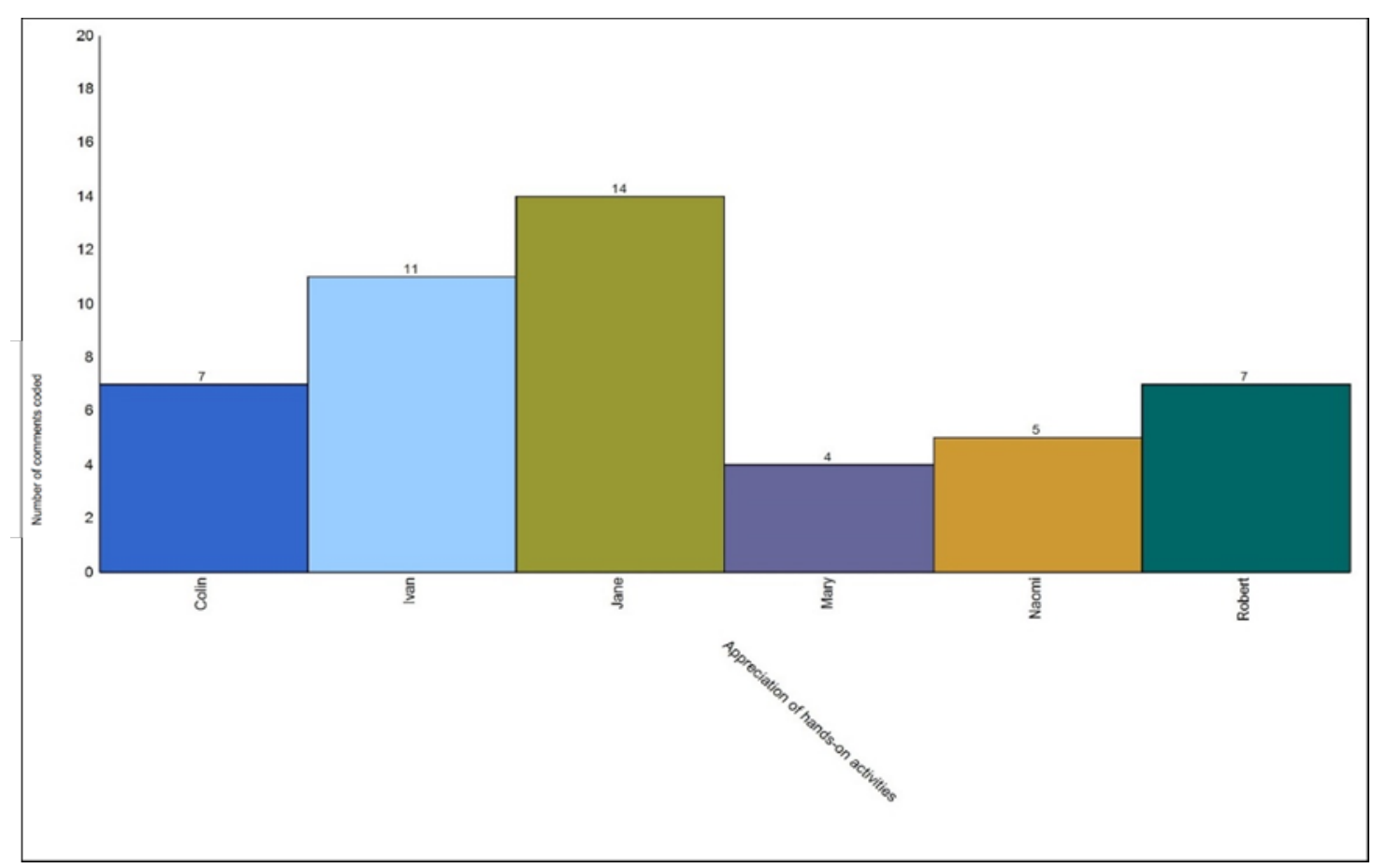

Figure 5. Number of comments on parental appreciation of STEM hands-on activities.

3.2.3 Parental confidence in their ability to support or mentor their children in STEM

Figure 6 shows the number of comments coded for "Parental confidence to provide their children with STEM support". All six interviewees reported having confidence to provide STEM support and mentorship to their children. However, their level of confidence was observed to vary.

Considering the participants who have not studied STEM-related subjects beyond secondary school, e.g. Colin, Mary and Naomi, the first was very confident, while the other two not so much. Colin reported having done experiments at home with his children on a regular basis and considered himself a "learning stimulator". Moreover, Colin's familiarity with the curriculum provided by the local home-school group and his personal interest in STEM made him even more confident. Mary reported having a limited knowledge of science. Still she would stimulate her children by recommending science-related videos and simulations from the Internet. To Mary, her children are so poorly prepared in school that even she can support and mentor them to a certain extent. Naomi reported taking her son to science centres regularly. Furthermore, her engineer husband is passionate about Lego and has passed that down to their son. The husband takes the lead when it comes to more scientific concepts. 
Of the participants who have STEM-related careers, e.g. Ivan, J ane and Robert, the latter reported having limited understanding of some of the recent technological tools needed in some of his son's school projects. Yet, he would make himself available so that they could master this knowledge together. Alternatively, he would put his son in contact with someone better acquainted with these tools. Ivan and J ane reported being very confident to support and mentor their children. Their support and mentorship come in many ways. Apart from helping with homework activities, both suggest websites their children can access to engage with STEM activities. Also, they use daily situations as opportunities to help their children develop and apply problemsolving skills.

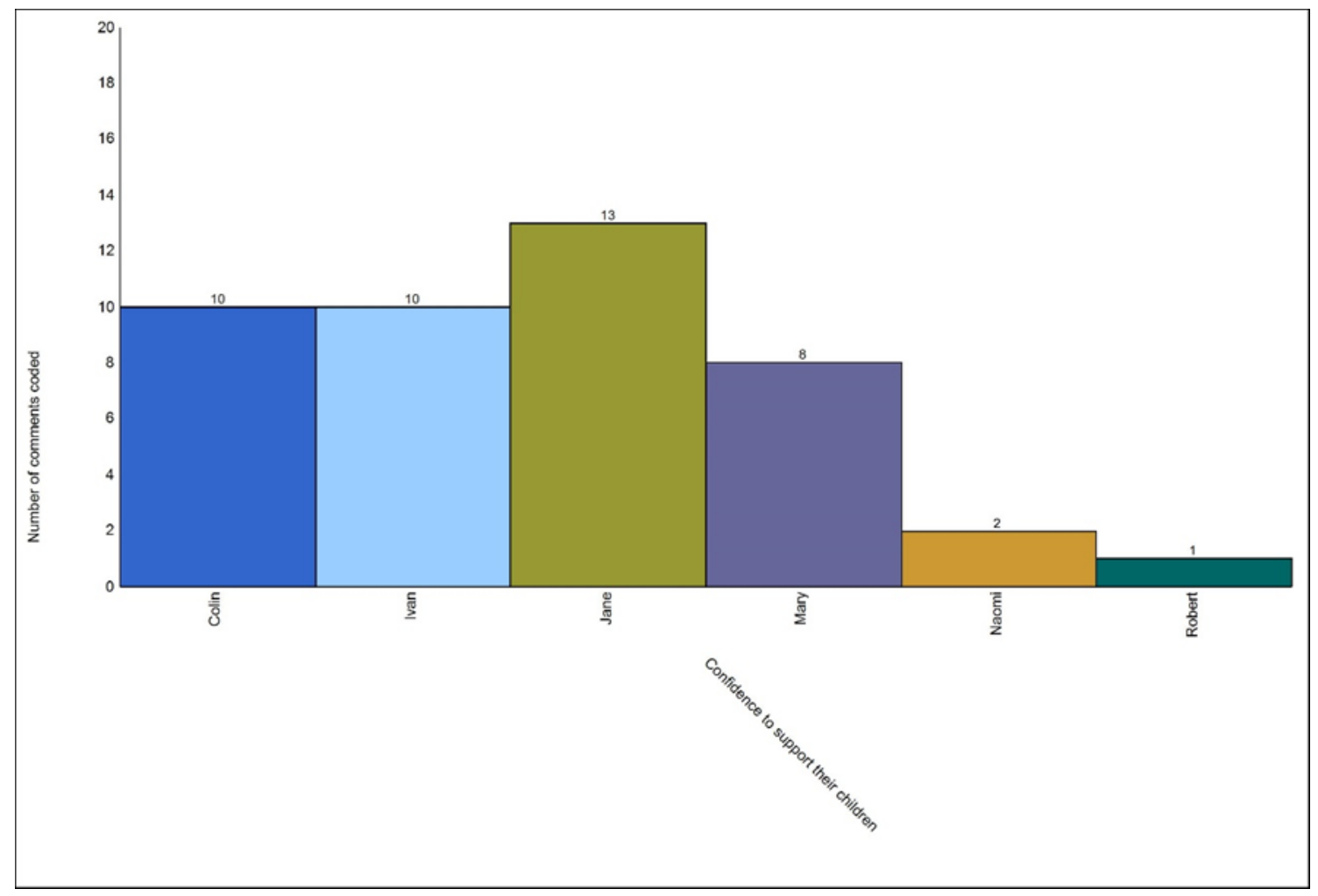

Figure 6. Number of comments on parental confidence to provide their children with STEM support.

3.2.4 Parents' knowledge of their children's school STEM curriculum and of BC K-12 educational approach

Figure 7 shows the number of comments coded for "Parental knowledge of their children's school STEM curriculum" and "Parental knowledge of British Columbia K12 educational approach". Even though British Columbia's official school K-12 curriculum is available online, that was not reported as an effective way for interviewees to learn about the contents of their children's STEM-related school 
programs. Instead, school-family, parent-child, and parent-teacher interactions were regarded as more efficient. Only two interviewees, Ivan and J ane, who are educators, were aware that BC K-12 schools are expected to incorporate inquiry-based learning into their practices.

Furthermore, Ivan reported having become familiar with his daughter's science program through projects and homework assignments. As an example, he reported a game-based project on animals in which "she learnt a lot". Robert also reported having become familiar with his son's school projects through their interactions at home. Moreover, he reported that his son's school informs parents about ongoing projects through email messages. He added that school-family communication is effective as it allows him to monitor his son's progress.

Jane, Naomi and Mary reported having accessed the online version of their children's school curriculum. However, that was not a meaningful experience for any of them. They also reported not having done that regularly. Naomi added that families were informed of their children's school curriculum at the beginning of the academic year when the school sent home a hard-copy version of the contents to be covered within the year. J ane described the online curriculum as "a tedious document". She also said that it was through conversations with her daughter and her teacher that she learnt about the school curriculum. Moreover, J ane reported to be more familiar with her daughter's mathematics than with the science curriculum. Mary is the one who showed the greatest discomfort about not having any information about her children's mathematics and science school programs. She tried to obtain some information by asking their teachers, but was told to go online. She did so, but could not establish any connection between the online documents and her children's oral accounts or their school materials. Colin claimed to be one hundred percent familiar with the BC K-12 curriculum. His children are home-schooled and he and his wife are in contact with a local homeschool group. 


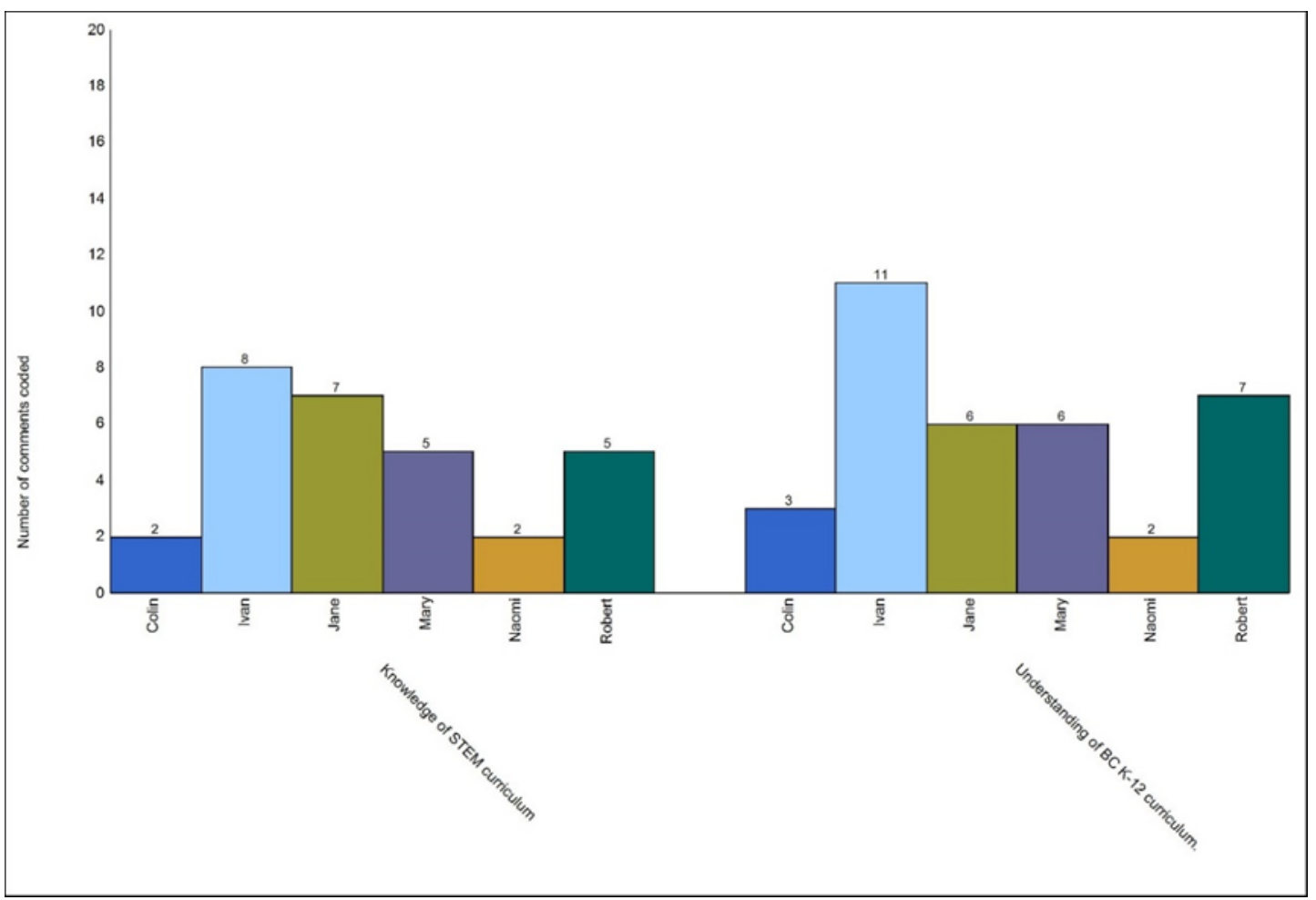

Figure 7. Number of comments on parental knowledge of their children's STEM curriculum and of BC K-12 educational approach

3.2.5 Parental level of comfort in communicating their concerns about their children with their STEM teacher

Figure 8 shows the number of comments coded for "Parental level of comfort to talk to their children's STEM teacher". All six interviewees expressed distinct levels of comfort regarding their experiences communicating with their children's teachers. Furthermore, they reported contacting the corresponding teachers for several reasons.

Mary was the least comfortable of all interviewees in communicating with her children's teacher. She spoke to her daughter's teacher to obtain information about the science contents as she was thought little science was being done. Furthermore, she reported being puzzled about her daughter having grades without having done much science-related work. For Mary, the teacher sounded very defensive and told her the course contents were the same for all Vancouver schools. She was quite unconvinced and disappointed with the outcomes of the conversation. Still, she would complain to avoid creating any animosity. Mary's J apanese background and limited command of English played a part in her decision. 
Naomi commented that her son's teacher from Kindergarten was more approachable and open to talk to parents than this year's Grade 1. To her, the current teacher "hides in the classroom" and keeps communication to a minimum. When flipping through her son's workbook in a parent-teacher interview, she was surprised by how little he had written up until that point. From then onward she demanded that the teacher sent the boy's workbook home every week. She was very disappointed to learn about her son's limited written production by chance. She added that she "doesn't want to be breathing down the teacher's neck", but expected the teacher to have been more pro-active in that regard.

Ivan and Jane, however, reported having approached their children's teacher whenever necessary without any apparent discomfort. For example, Ivan asked about how the inquiry-based approach suggested by BC School Board would be put into practice. Jane, in turn, asked how her mathematics-gifted daughter was being challenged to further develop her potential.

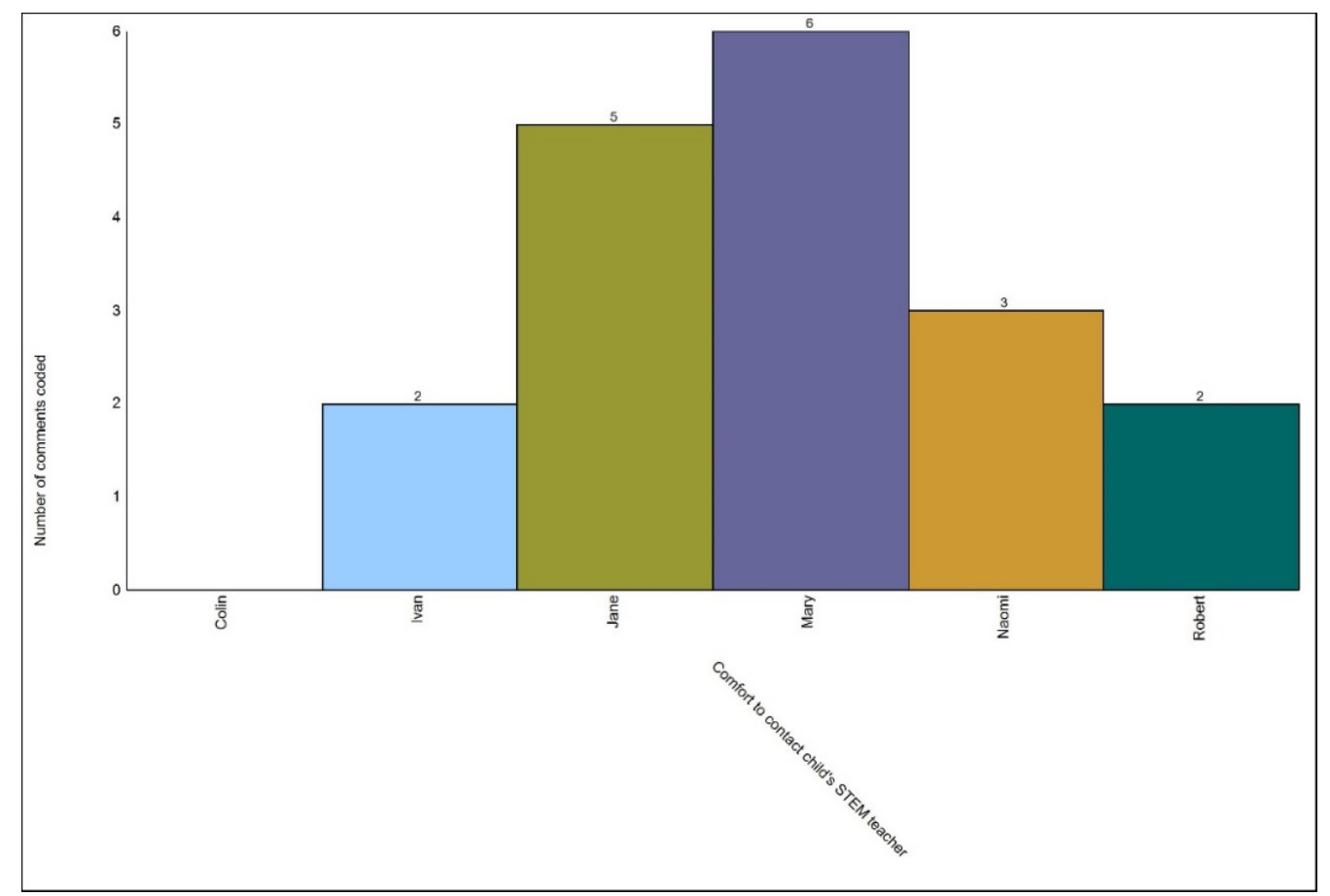

Figure 8. Number of comments on parental level of comfort to contact their children's STEM teacher. 
3.2.6 Parental satisfaction of their children's STEM education and parental view of how well their children are being prepared in school for future STEM education

Figure 9 shows the number of comments coded for "Parental satisfaction with their children's STEM education" and for "Parental views on how well their children are being prepared for future STEM education". As mentioned before, Mary was by far the most dissatisfied interviewee with her children's formal STEM education. She was particularly worried about her grade 7 daughter not being able to keep up with the demands of secondary school in future. To address this issue, Mary enrolled her daughter in a preparatory course. Mary even reported that many other parents whose children go to the same school as her daughter have done the same.

Ivan's daughter had recently moved to a school in East Vancouver (a less affluent area). For him, her former school in West Vancouver was more effective in science teaching, particularly regarding outdoor learning. School projects were also believed to be better elaborated. Moreover, Ivan's daughter's current school was reported to be more traditional in its educational approach. Ivan gave two examples to illustrate his dissatisfaction with his daughter's current teacher. One relates to the way she was evaluated in a science activity, the other regards the teacher's lack of preparation to effectively put the inquiry-based pedagogy into practice. Despite all that, Ivan considered that his daughter was being properly prepared for future STEM education due to the extra enrichment provided by the family.

Robert was pleased with his son's formal STEM education, especially after his moving to a school that offered the Sail (Science, Arts and Innovative Learning) Program. This school places great emphasis on STEM-related subjects and this was the main motivation behind the moving. J ane reported being satisfied with her daughter's formal STEM education. As the daughter is gifted in mathematics, J ane's only concern related to whether the daughter was being properly challenged. After speaking to the teacher, she learnt that the daughter was given extra, more advanced tasks. Furthermore, the girl was asked to provide support to some classmates. Naomi reported being somewhat familiar with her son's math and science curriculum. Yet, she was confident that her son's formal education together with the enrichment and support provided by the family would be enough to prepare the boy for future STEM education. Colin demonstrated great satisfaction with his daughters' STEM education. Their success is accredited to the fact that they are homeschooled. For him, 
the activities they do as a family surpass the ones suggested by the local homeschool group.

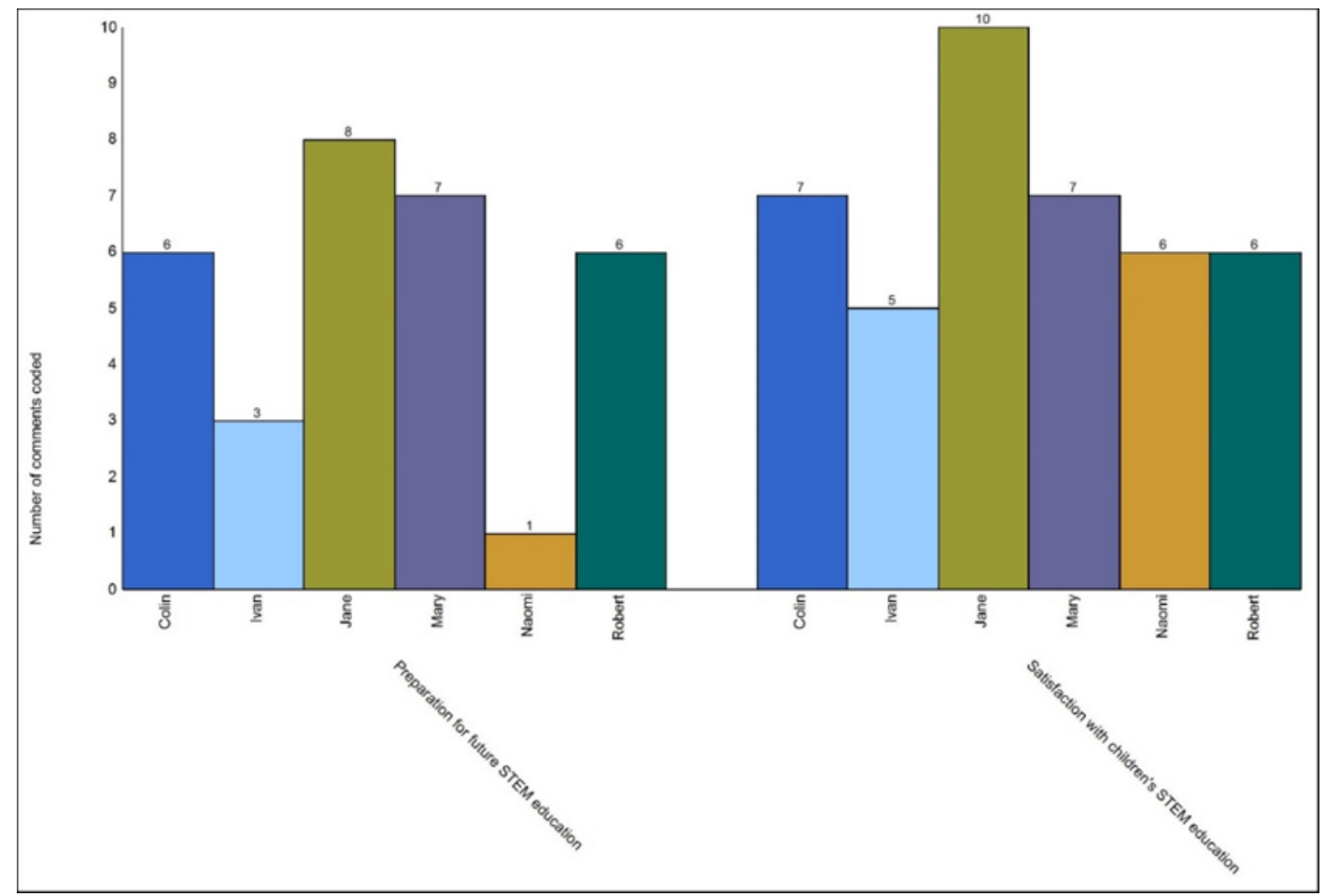

Figure 9. Number of comments on parental satisfaction with their children's STEM education and on how well their children are being prepared for future STEM education.

\section{Analysis of Results and Discussion}

Below we examine the results obtained from the questionnaire and the interviews. We also examine the correlations between the results pertaining to each of the four research questions of the study in order to understand the big picture of parental attitudes about STEM and their motivation to engage their children in STEM activities.

\subsection{RQ1: What are parents' attitudes towards informal STEM education?}

Questionnaire respondents showed great appreciation for FMSD and selected many reasons and ways to engage their children with STEM. These reasons will be further discussed below in the answer to research question 2 (RQ2). Interviewees, in turn, emphasised their positive attitude towards STEM regardless of having STEM-related careers. Furthermore, all interviewees demonstrated interest in providing their 
children with informal STEM enrichment. Taking their children to science centres and to outreach events after school hours and during weekends was reported to be an integral part of their family routines. Moreover, all interviewees reported doing STEM-related activities at home with their children. These included school-related projects and extra-curricular activities such as experiments, demonstrations, watching videos, accessing websites, using applications etc.

\subsection{RQ2: From parents' perspectives, what are effective ways to engage their children in STEM education?}

Four of the six interviewees reported being current or former members of Vancouver Science World. The Vancouver Aquarium was also named as an important family destination. Other science centres, e.g., Beaty Biodiversity Museum, Botanical Garden, The Exploration Place in Prince George, Pacific Science Center in Seattle and The Exploratorium in San Francisco, were also mentioned. All six interviewees reported taking their children to STEM-related outreach events. Apart from UBC's FMSD and The Faraday Science Show, Lego shows and science outreach events at Simon Fraser University were also mentioned. After-school activities and courses sponsored by the School Boards or private organizations were also reported. These involve outdoor-learning activities, math clubs, summer camps, robotics, course in the Vancouver Aquarium, and activities with animals. In line with that, questionnaire respondents considered taking their children to science centres (89.7\%) and encourage them to participate STEM-related outreach events (89.7\%), as the two most important ways to support their children with STEM studies. Those were followed by helping with STEM-related homework assignments (82.6\%), asking what children are learning in school (75.9\%), encouraging children to watch STEM-related programming (72.4\%), connecting STEM to important societal and political issues (62.1\%), and enrolling children in after-school STEM-related programs (51.7\%).

All six interviewees acknowledge the importance of hands-on interactive activities for children. For them, such activities are effective to: a) raise curiosity and interest; b) facilitate learning; and c) instill an exploratory mindset. For interviewees, FMSD was exemplary due to its interactive hands-on approach, the variety of available activities, and the presence of facilitators. Likewise, all 29 questionnaire respondents would recommend the event to others. 


\subsection{RQ3: What motivates parents to engage their children with STEM education?}

Discussing their motivation to engage their children with STEM, questionnaire respondents chose the following arguments as the most relevant: (1) STEM has many applications in everyday life (93.1\%); (2) STEM provides interesting ways to learn about the natural world (89.7\%); (3) STEM is fun (89.7\%); (4) STEM is at the core of technological innovations (82.8\%); and (5) STEM helps students develop critical thinking (86.2\%). It is important to highlight that STEM-related job opportunities or university admission requirement were not among the major motivating factors for the questionnaire respondents. Only $48.3 \%$ of them selected the former factor whereas $31.0 \%$ chose the latter. Even fewer respondents (13.8\%) expected their children to follow in their "STEM-related footsteps". Likewise, the six interviewees were more appreciative of the knowledge and skills STEM can offer than of its impact on university admission or future careers. Given that their children were of pre-school or elementary-school age, this is understandable. Furthermore, all interviewees were observed to be confident enough to provide STEM support and mentorship to their children. Their confidence was not observed to be related to whether participants had studied STEM-related subjects beyond secondary school. Below are some examples.

Colin reported having done experiments at home with his children on a regular basis and considered himself to be a "learning stimulator" to them. Mary reported having limited science knowledge. Still she would stimulate her children by showing some science-related videos and simulations from the Internet. In her view, her children are so poorly prepared in school that even she can support and mentor them. Naomi, in turn, reported that her engineer husband takes the lead when it comes to specific STEM contents. Robert reported having a limited understanding of modern technology required for some of his son's school projects. Yet, he would always make himself available so that he and his son could learn how to use the technological tools together. Ivan and J ane reported being very confident to support and mentor their children. Their support and mentorship come in many ways. Apart from helping with homework activities, both regularly suggest additional STEM-related resources to their children. Also, they use everyday life situations as opportunities to help their children develop problem-solving skills, thus connecting STEM to their lives. 


\subsection{RQ4: From parents' perspectives, what are effective ways for schools to encourage parents to support their children's STEM education?}

Questionnaire respondents considered the following ways as the most effective for schools to encourage parents to support their children: (1) Promoting STEM events at school (86.2\%); (2) Informing parents about activities in science centres (82.8\%); (3) Creating a classroom blog for parents to access from home (72.4\%); and (4) Establishing a direct line of communication between teacher and parents (65.5\%). Besides, 26 questionnaire respondents (89.6\%) considered parental involvement in STEM education either "very important" or "important". Interestingly, teacher-parent communication, or lack of thereof, was a sensitive matter for two of the six interviewees, Mary and Naomi. They reported being uncomfortable and disappointed with the responses they obtained from their children's school teachers. Ivan and J ane, however, dealt with sensitive issues with teachers in a straightforward confident manner.

Even though BC K-12 curriculum is available online, that was not reported to be an effective way for interviewees to become familiar with their children's school STEM programs. Ivan and Robert, for example, reported having become familiar with their children's science curriculum through projects or homework assignments done together at home. J ane, Naomi and Mary, on the other hand, reported having accessed the online version of their children's school curriculum. However, that was not a meaningful experience for them, and consequently they did not do that on a regular basis. Mary is the one who showed the greatest discomfort about not having any information about her children's mathematics and science school programs. She tried to obtain some information by asking the teachers, but was told to consult the online documents by the Ministry of Education. She did so, but could not find any connection between that curriculum and her children's actual STEM school programs.

\section{Conclusions and Implications for Practice}

Given that all study participants attended the FMSD, which is a STEM outreach event, it is not surprising that they held positive views about formal and informal STEM education. To corroborate that, interviewees made a substantial number of comments further emphasising their positive attitudes towards STEM. Moreover, all study participants believed that taking their children to outreach events and science centres 
are the most effective ways to engage them with STEM.

Questionnaire respondents chose the following reasons for encouraging their children to study STEM, as it: has various everyday life applications (93.1\%); opens interesting ways to learn about the natural world (89.7\%); is fun (89.7\%); is at the core of technological innovations (82.8\%); helps students develop critical thinking (86.2\%); and opens exciting and well-paid career opportunities (48.3\%). Likewise, interviewees emphasised the importance of the knowledge and skills STEM can offer children over STEM's connection to university courses and future careers. The argument valuing STEM-related subjects as the prerequisite for university admission was only selected by $31 \%$ of the questionnaire respondents. Moreover, questionnaire findings indicated that the parents who had STEM-related careers did not necessarily expect their children to follow in their footsteps (13.8\%). Questionnaire respondents also selected the following options for supporting their children STEM education: helping with homework assignments (82.6\%); asking about what children are learning in school (75.9\%); encouraging children to watch STEM-related shows (72.4\%); connecting STEM to important societal and political issues (62.1\%); and enrolling children in after-school programs (51.7\%).

Another interesting finding highlights the importance of hands-on interactive activities, which was a key element of FMSD. All study participants rated the event as either very interesting (79.3\%) or interesting (21.7\%). Besides, all of them would recommend FMSD to others. Moreover, all the interviewees praised the way FMSD was set up. For them, having interactive activities was a key aspect of the event's success. This explains why interactive STEM engagement has become an increasingly important part of STEM outreach worldwide. Additionally, study participants acknowledged the importance of parental participation in their children's formal and informal STEM education. Thus, as an important implication for practice, it is crucial that schools and science outreach providers find ways to connect with the students' families, reaching to the parents as well as to the children. However, more than onethird of the participants (35.7\%) considered themselves "unfamiliar" with their children's school STEM curriculum. Moreover, the availability of an online version of the official curriculum was insufficient for the participants to learn about their children's school STEM programs. For them school-family, parent-teacher, and parent-child interactions were more efficient channels of communication. This also has important practical implications for STEM educators, educational administrators and STEM outreach providers. 
Questionnaire respondents considered the following ways as the most effective to encourage parents to support their children's STEM education: Promoting STEM events at school (86.2\%); Informing parents about activities in science centres (82.8\%); Creating a classroom blog for parents to access from home (72.4\%); and Establishing a direct line of communication between teachers and parents (65.5\%). Based on these findings, we would like to make the following recommendations to help educators, parents and policy-makers promote STEM education:

1. Many parents who would like to support their children may lack STEM expertise or even information on what can be done and how regarding both formal (in-school) and informal (out-of-school) settings. Therefore, providing parents with details about school STEM programs, for example, should encourage parental participation in their children's education. To achieve this, school-family, teacher-parent, and student-parent interactions seem to be more effective than making an online version of the school curriculum available.

2. Informing parents of STEM-related outreach events, such as FMSD or exhibitions at science centres, provides families with meaningful opportunities to engage with STEM. Such family outings are effective in facilitating cognitive as well as affective and emotional learning.

3. Interactive hands-on activities are effective in raising STEM interest in children and parents alike. Such educational approach should be encouraged in formal and informal settings. To make this approach effective, STEM facilitators must be acquainted not only with activity procedures, but also with the corresponding scientific explanations and implications.

4. Interactive hands-on STEM activities such as the ones promoted by science centres and outreach events are valuable not only for the public, but also for the activity facilitators. In the case of FMSD, activity facilitators are mostly teacher-candidates who have a sound theoretical knowledge of inquiry-based learning but little experience putting that knowledge into practice. One of the main motivations behind the creation of FMSD was to provide teachercandidates with such opportunities. Our experience over the years has shown that teacher-candidates find it beneficial to go through the experience of setting up and carrying out the activities, as well as interacting with the public. Thus, it is desirable that teacher education programs find ways to equip STEM 
professionals with the knowledge and skills to effectively interact with visitors/learners in a meaningful way.

\section{Future directions}

The study was focused on examining the motivation behind parental engagement in out-of-school STEM outreach. It also has revealed some challenges experienced by the parents who wanted to support their children in STEM. As parents play an important role in the educational decisions of their children, it is important to consider how these challenges can be addressed. In the follow-up studies, we are planning to investigate these challenges more carefully and propose practical solutions. We are convinced that this line of research will bring valuable insights to STEM education community and will support STEM education of our students.

\section{Limitations}

This study has several limitations. First, the participants are event attendees, who are already interested in STEM education. This could have an impact on the study outcomes. Second, only twenty-nine parents volunteered to participate in the study. This relatively small number of participants limits results' generalizability.

\section{Acknowledgments}

Financial support for this study was provided by the University of British Columbia Teaching and Learning Enhancement Fund.

\section{References}

Fine, M. (1993). Apparent Involvement: Reflections on Parents, Power, and Urban Public Schools. Teacher's College Record, 94(4), 711.

Hathaway, I., \& Kallerman, P. (2012). Technology Works: High-Tech Employment and Wages in the United States. Retrieved from http:/ / www.bayareaeconomy.org/ files/ pdf/TechReport.pdf

Ing, M. (2014). Can parents influence children's mathematics achievement and persistence in STEM careers? J ournal of Career Development, 41(2), 87- 103.

Kaya, S., \& Lundeen, C. (2010). Capturing parents' individual and institutional interest toward involvement in science education. J ournal of Science Teacher Education, 21, 825- 841. doi:10.1007/s10972-009-9173-4 
Let's Talk Science. (2013). Spotlight on science learning: The high cost of dropping science and math. Retrieved from http:/ / www.letstalkscience.ca/ our-research/ spotlight2013.html

Let's Talk Science. (2015). Exploring parental influence: Shaping teen decisions regarding science education. Retrieved from

http:/ / www.letstalkscience.ca/ Portals/ 0/ Documents/ RPS/ Spotlight/LTS-Exploringparental-influence-EN.pdf

Let's Talk Science. (2017). Canada-2067: The science of a successfull tomorrow. Retrieved from https:/ / canada2067.ca/ en/

Mathison, S. (1988). Why triangulate? Educational Researcher, 17(2), 13-17.

Milner-Bolotin, M. (2017). Science \& Math Education Videos for All. YouTube Channel of Online STEM resources. Retrieved from https:/ / www.youtube.com/ channel/UCHKp2Hd2k dLjODXydn2-OA

Milner-Bolotin, M., \& Milner, V. (2017). Family Mathematics and Science Day at UBC Faculty of Education. Physics in Canada, 73(3), 130- 132.

O'Grady, K., Deussing, M.-A., Scerbina, T., Fung, K., \& Muhe, N. (2016). Measuring up: Canadian Results of the OECD PISA Study: The performance of Canada's youth in science, reading and mathematics (2015 First Results for Canadians Aged 15). Toronto. ON: Council of Ministers of Education, Canada.

Perera, L. D. H. (2014). Parents' attitudes towards science and their children's science achievement. International J ournal of Science Education, 36(18), 3021- 3041. doi:10.1080/09500693.2014.949900

QSR International. (2016). NVivo 11 for Windows. Retrieved from http:/ / www.qsrinternational.com/ products_nvivo.aspx

The National STEM Learning Network. (2017). Supporting STEM Learning. Project ENTHUSE. Retrieved from https:/ / www.stem.org.uk 


\section{Appendix}

\section{Helping Your Kids Succeed in Math \& Science}

This questionnaire is part of a research project being carried out in the Department of Curriculum and Pedagogy (Faculty of Education) at the University of British Columbia. The goal of the study is to investigate how we can enhance parental engagement in their children mathematics and science education to support each and every student.

This project is led by Author (email). It will take you about 10 minutes to complete. Thank you for your cooperation.

1. What best describes your relationship with the child/children you have been accompanying to this event?

\begin{tabular}{|l|l|}
\hline ( ) parent or legal guardian. & ( ) other family member. \\
\hline ( ) grandparent. & ( ) family friend. \\
\hline ( ) Other. & \\
\hline
\end{tabular}

2. What is your age group?

\begin{tabular}{|l|l|l|l|}
\hline ( ) 19-24 & ( ) 25-34 & ( ) 35-44 & ( ) 45-54 \\
\hline ( ) 55-64 & ( ) 65-74 & $($ ) $75+$ & \\
\hline
\end{tabular}

3. Where were you born?

\begin{tabular}{|l|l|l|}
\hline ( ) Canada & ( ) USA & ( ) Mexico \\
\hline ( ) Latin America & ( ) Middle East & ( ) Asia \\
\hline ( ) Oceania & ( ) Africa & ( ) Europe \\
\hline
\end{tabular}

4. What is the highest level of math course you took in secondary school?

( ) The only level of math course offered by my school.

( ) The highest level math course offered by my school (for example, calculus).

( ) The intermediate level math course offered by my school (for example, pre-calculus).

( ) The lowest level math course offered by my school (for example, algebra).

( ) I didn't take any math courses in secondary school.

5. What's the highest level of math that you studied beyond elementary school?

( ) I didn't study math beyond elementary school (or equivalent).

( ) Secondary school math.

( ) Undergraduate level (college or university).

( ) Graduate level (Master's or PhD). 
6. What's the highest level of science that you studied beyond elementary school?

( ) I didn't study science beyond elementary school (or equivalent).

( ) Secondary school science.

( ) Undergraduate level (college or university).

7. Which Family Math \& Science Day events have you attended in past? (Please select all that apply)

\begin{tabular}{|l|l|l|l|}
\hline ( ) 2010 & ( ) 2011 & ( ) 2012 & ( ) 2013 \\
\hline ( ) 2014 & ( ) 2015 & ( ) 2016 & $\begin{array}{l}\text { ( ) I haven't } \\
\text { attended any of the } \\
\text { events. }\end{array}$ \\
\hline
\end{tabular}

8. What is your general impression of the event?

\begin{tabular}{|l|l|l|}
\hline ( ) Very interesting. & ( ) Interesting. & ( ) Not so interesting. \\
\hline
\end{tabular}

9. Would you recommend other families to attend this event in the future?

\begin{tabular}{|l|l|l|}
\hline ( ) Yes. & ( ) I'm not sure. & ( ) No. \\
\hline
\end{tabular}

10. Why would you encourage your child to study math \& science? (Select all that apply.)

( ) Math \& science are fun.

( ) Math \& science provide an interesting way to learn about the natural world.

( ) Math \& science have many everyday life applications.

( ) Math \& science are at the core of modern innovations (technologies, etc.).

( ) Math \& science will open many exciting and well paid job opportunities for children.

( ) Math \& science help students to develop critical thinking skills.

( ) Math \& science are required courses for university admission.

( ) Your own profession/occupation is related to math \& science and you'd like your child to follow in your footsteps.

( ) Other.

11. What are effective ways for parents/families to encourage their children to study math and science? (Select all that apply.)

( ) Taking children to science museums, aquariums or other math- or science-related events.

( ) Asking children about what they've been learning in their math or science classes at school.

( ) Helping children with their math and science homework assignments.

( ) Enrolling children in after-school math and science programs.

( ) Pointing out the role math \& science play in dealing with important societal and political issues (news, etc.).

( ) Encouraging children to watch math \& science-related shows, such as Cosmos, the Animal Planet, etc.

( ) Accompanying children to math- and science-related events such as this one.

( ) Other. (Please specify) 
12. How can schools encourage parents to support their children in math \& science education? (Select all that apply.)

( ) Assigning homework activities that require parental involvement or support.

( ) Establishing a direct line of communication, by email messages, for example, between teacher and parents to enable parents to get some feedback on their children's progress in science and math.

( ) Creating a classroom blog parents can access from home to find out what students are doing in math and science at school.

( ) Informing parents about math- and science-related activities in museums, for example, parents can visit with their children.

( ) Promoting math- and science-related events in school (i.e. science fair) for parents to visit.

( ) Other. (Please specify)

13. How familiar are you with the math \& science school curriculum offered by your child's school?

\begin{tabular}{|l|l|l|}
\hline ( ) Very familiar. & ( ) Somewhat familiar. & ( ) Not familiar at all. \\
\hline
\end{tabular}

14. How important is parental involvement in math \& science education of their children?

\begin{tabular}{|l|l|l|}
\hline ( ) Very important. & ( ) Important. & ( ) Somewhat important. \\
\hline ( ) It is not very important. & ( ) It is not important at all. & \\
\hline
\end{tabular}

15. Please share with us your general feedback and suggestions about the event.

16. Would you allow us to contact you to discuss how we can improve math \& science opportunities for your children?

( ) yes ( ) no.

17. If your answer to question 15 is YES, and you would like to discuss your ideas with us, please leave your first name and email address (or phone number) in the space below. We will be happy to contact you.

\begin{tabular}{|l|l}
\hline Name: & Contact number/address:
\end{tabular}

